\title{
Article \\ Functional Characterization of Marigold Powder as a Food Ingredient for Lutein-Fortified Fresh Noodles
}

\author{
Seungkyun Nam ${ }^{1}$, Chan-Yang Lee ${ }^{1}$, Soon-Mi Shim ${ }^{1}$, Dong-Un Lee ${ }^{2}{ }^{\mathbb{D}}$ and Suyong Lee ${ }^{1, *}$ \\ 1 Carbohydrate Bioproduct Research Center, Department of Food Science \& Biotechnology, Sejong University, \\ Seoul 05006, Korea; qpua333@nate.com (S.N.); cks445@naver.com (C.-Y.L.); \\ soonmishim@sejong.ac.kr (S.-M.S.) \\ 2 Department of Food Science and Technology, Chung-Ang University, Gyeonggi-Do, Anseong 456-756, Korea; \\ dong-un.lee@cau.ac.kr \\ * Correspondence: suyonglee@sejong.ac.kr; Tel.: +82-2-3408-3227
}

Citation: Nam, S.; Lee, C.-Y.; Shim, S.-M.; Lee, D.-U.; Lee, S. Functional Characterization of Marigold Powder as a Food Ingredient for Lutein-Fortified Fresh Noodles. Appl. Sci. 2021, 11, 861. https://doi.org/10.3390/ app11020861

Received: 5 January 2021

Accepted: 15 January 2021

Published: 18 January 2021

Publisher's Note: MDPI stays neutral with regard to jurisdictional claims in published maps and institutional affiliations.

Copyright: (c) 2021 by the authors. Licensee MDPI, Basel, Switzerland. This article is an open access article distributed under the terms and conditions of the Creative Commons Attribution (CC BY) license (https:// creativecommons.org/licenses/by/ $4.0 /)$.

\begin{abstract}
Marigold powder was utilized as a food ingredient to produce lutein-fortified fresh noodles for eye health, and its functionalities were characterized in terms of thermo-rheological, structural, and antioxidant properties. The pasting parameters and starch-gelatinization enthalpy values of wheat flour had a tendency to decrease with increasing levels of marigold powder. The use of marigold powder led to decreases in the storage and loss moduli of wheat flour pastes by weakening their cellular microstructure, which was confirmed by the scanning electron microscopic images. When marigold powder was incorporated into the formulation of fresh noodles, the cooking loss and water absorption of the noodles were not negatively affected at a level of $2 \%(w / w)$. Also, the noodles with $2 \%$ marigold powder were not significantly different from the control for the maximum resistance to extension. The levels of lutein in the noodles prepared with marigold powder (61.2 to $204.9 \mathrm{mg} / 100 \mathrm{~g}$ ) were reduced by almost 50\% after cooking. However, they seemed to satisfy the recommended daily dose of lutein for visual functions. Moreover, the use of marigold powder provided antioxidant properties for noodles by enhancing the $2,2^{\prime}$-diphenyl-1-picrylhydrazyl (DPPH) and 2,2-azino-bis-3-ethylbenzothiazoline-6-sulfonic acid (ABTS) radical-scavenging activities.
\end{abstract}

Keywords: marigold; lutein; noodle; rheology; structure

\section{Introduction}

Frequent exposure to various digital devices, such as smartphones and computers, may cause humans to experience digital eye strain (including blurred vision and eye fatigue), which is commonly linked to eye-related diseases [1]. In addition to the use of digital devices, aging [2] is recognized to be a primary factor increasing the risks to eye health. While age-related macular degeneration is a leading cause of blindness in the population over 65 years of age, the number of macular degeneration patients is steadily increasing every year [3]. Therefore, the global market of vision care is dramatically on the rise, and it is expected to reach approximately US $\$ 74$ billion by 2024 [4].

Health-conscious consumers have recently shifted the focus of the food industry to functional foods with beneficial health effects, since the bioactive compounds in foods are recognized to be very effective in reducing the risk of disease incidence and preventing illness [5]; the foods for eye health and eyesight are no exceptions. As a type of carotenoid, lutein is a major pigment in the macular region of the retina [6]. In addition, since lutein has an antioxidant effect that removes free radicals, it is recognized to prevent damage to the retinal cells [7]. Gale, et al. [8] reported that lutein played a significant role in promoting the health of the eyes, reducing the risk of age-related macular degeneration. It was also reported that lutein had great abilities to block blue light and to positively affect immune responses and inflammation [9]. However, since lutein cannot be synthesized by the body, it must be obtained from the diet [10]. It is known that lutein is available naturally in fruits, 
cereals, and vegetables [11]. Marigold (Tagetes erecta L.) is also recognized to be a rich source of lutein. Thus, marigold powder has been commercially used as a nutritional supplement in capsules and tablets [12]. However, the applications of marigold powder to food products are very limited. Kumar et al. [13] incorporated marigold powder $(0.40-0.55 \%)$ to milk-based beverages whose physicochemical and sensory properties were characterized. The rheological changes of wheat flour by marigold powder were also reported [14]. However, there are no systematic studies about the processing performance of marigold powder high in lutein in a food system, which is typically subjected to a variety of processing conditions such as heat treatments and mixing with other ingredients. Consequently, the food industry may be discouraged to develop a variety of food products to maintain good eyesight and eye health.

In this study, marigold powder was incorporated as a source of lutein into the formulation of fresh noodles for lutein fortification, and its functionalities were investigated in terms of thermo-rheological, structural, and antioxidant properties.

\section{Materials and Methods}

\subsection{Materials}

Marigold powder was obtained from Fell Nature Inc. (Gyeonggi-do, Korea), and its chemical composition consisted of $0.16 \%$ protein, $8.59 \%$ lipid, $0.21 \%$ ash, and $5.92 \%$ moisture, which were determined by the Association of Official Analytical Chemists (AOAC)-approved method. In addition, all-purpose wheat flour (CJ Co. Ltd., Seoul, Korea) was obtained from a commercial source. All the chemicals used in this study were of analytical grades.

\subsection{Pasting Property Measurement}

The effect of marigold powder on the pasting pattern of wheat flour was evaluated using a starch pasting cell that was linked to a controlled-stress rheometer (Discovery HR-2 hybrid rheometer, TA instrument, New Castle, DE, USA). The wheat flour was replaced with marigold powder $(0,2,4$, and $6 \% w / w)$. Each flour sample $(3 \mathrm{~g})$ was suspended in in distilled water $(25 \mathrm{~g})$. The suspension was equilibrated at $50{ }^{\circ} \mathrm{C}$ for $1 \mathrm{~min}$ and then heated to $95^{\circ} \mathrm{C}$ at a rate of $12{ }^{\circ} \mathrm{C} / \mathrm{min}$. This was followed by holding at $95^{\circ} \mathrm{C}$ for $5 \mathrm{~min}$, cooling to $50{ }^{\circ} \mathrm{C}$ at $12{ }^{\circ} \mathrm{C} / \mathrm{min}$, and maintained at $50^{\circ} \mathrm{C}$ for $2 \mathrm{~min}$.

\subsection{Thermal Analysis}

The thermal properties of the wheat flour containing marigold powder at $0,2,4$, and $6 \%$ by weight were investigated using differential scanning calorimetry (DSC) (DSC 200 F3 Maia, NETZSCH, Bavaria, Germany). The marigold powder-wheat flour mixture (5 mg) was held in an aluminum pan and distilled water $(15 \mu \mathrm{L})$ was added. After the pan was hermetically sealed, it was held at room temperature for $1 \mathrm{~h}$ for stabilization and then heated from 20 to $120^{\circ} \mathrm{C}$ at $10{ }^{\circ} \mathrm{C} / \mathrm{min}$.

\subsection{Dynamic Viscoelastic Measurement}

Right after the pasting measurement, the dynamic viscoelastic properties of the wheat flour-marigold powder pastes were investigated using a controlled-stress rheometer (Discovery HR-2 hybrid rheometer, TA instrument, New Castle DE, USA). A frequency sweep test was carried out at $30^{\circ} \mathrm{C}$ in the frequency range from 0.1 to $10 \mathrm{~Hz}$ at a strain of $0.1 \%$, which was within the linear viscoelastic regime.

\subsection{SEM Analysis}

The effect of marigold powder on the microstructure of the wheat flour pastes was investigated using a scanning electron microscope (TM4000Plus, Hitachi High-Technologies, Tokyo, Japan). The wheat flour pastes where the wheat flour was replaced with marigold powder at $0,2,4$, and $6 \%(w / w)$ were freeze-dried, and the microscope was operated at a magnification of $\times 1000$ at a $15 \mathrm{kV}$ accelerating voltage. 


\subsection{Preparation of Fresh Noodles}

The control of the fresh noodles was prepared with $50 \mathrm{~g}$ of wheat flour, $1 \mathrm{~g} \mathrm{NaCl}$ (CJ Co.), and $20 \mathrm{~mL}$ of distilled water. The wheat flour was replaced with marigold powder $(0,2,4$, and $6 \% w / w)$. All the ingredients were mixed using a mixer (Kitchen Aid Inc., St. Joseph, MI, USA) at speed two for $3 \mathrm{~min}$, and the dough sample was sheeted with a sheeting roller $(1.4 \mathrm{~mm})$, which was followed by cutting into noodle strands (4 $\mathrm{mm}$ wide and $50 \mathrm{~mm}$ long). The noodle strands $(5 \mathrm{~g})$ were cooked in hot distilled water $(150 \mathrm{~mL})$ for 3 and $6 \mathrm{~min}$, and then drained in a strainer for $5 \mathrm{~min}$.

\subsection{Cooking Property Measurement}

The fresh noodle samples ( $5 \mathrm{~g}, 5 \mathrm{~cm}$ long) were immersed in $150 \mathrm{~mL}$ of boiling water for 3 and $6 \mathrm{~min}$, followed by draining in a strainer for $5 \mathrm{~min}$. The cooking water collected was dried at $105^{\circ} \mathrm{C}$ for $6 \mathrm{~h}$, and the residue was then weighed. The cooking loss and water absorption were determined based on the following equations:

$$
\text { Cooking loss }(\%)=\text { weight of cooking water after drying } \times 100 / \text { weight of uncooked noodle }
$$

Water absorption $(\%)=($ weight of cooked noodle - weight of uncooked noodle $) \times 100 /$ weight of uncooked noodle

\subsection{Tensile Measurement}

The effect of marigold powder on the tensile properties of the noodles was investigated using a texture analyzer (TA-XT plus, Stable Micro System Ltd., Godalming, UK). After cooked for $6 \mathrm{~min}$, the noodles were subjected to a tensile test using a Kieffer dough and gluten extensibility rig. While the noodle strand was extended at $200 \mathrm{~mm} / \mathrm{min}$, the maximum resistance force to extension (Rmax) and extensibility (E) were recorded from the curves of force versus distance.

\subsection{HPLC Analysis of Lutein}

According to the method of Liu et al. [15] and Moros et al. [16], with slight modifications, the level of lutein in marigold powder and noodles was quantitatively analyzed using high-performance liquid chromatography (HPLC, Ultimate 3000, Dionex, CA, USA) with a UV detector and a C30 column (CT99S05-2546WT, YMC Co. Ltd., Kyoto, Japan). For analyzing the level of lutein in the noodles, the noodles were freeze-dried and ground to pass through a 100-mesh sieve. The marigold or the noodle powder $(0.1 \mathrm{~g})$ was treated with $25 \mathrm{~mL}$ of $70 \%$ ethanol, and butylated-hydroxy-toluene $(10 \mathrm{mg})$ was added to avoid the oxidation of the lutein. The sample was agitated at $50{ }^{\circ} \mathrm{C}$ for $4 \mathrm{~h}$ and centrifuged at $4500 \times g\left(4{ }^{\circ} \mathrm{C}, 15 \mathrm{~min}\right)$. After the supernatant was collected, the residue was re-treated with $70 \%$ ethanol one more time. All the ethanolic extracts were combined and evaporated using a nitrogen evaporator (Organomation, Berlin, MA, USA) at $40^{\circ} \mathrm{C}$. The concentrated extracts were eluted with the use of two mobile phases that consisted of methanol/MTBE/water $(81: 15: 4, v / v / v)$ (solvent A) and methanol/MTBE $(9: 91, v / v)$ (solvent B). After being dissolved in $2 \mathrm{~mL}$ of solvent $\mathrm{A}$, the samples were filtered with $0.45 \mathrm{um}$ syringe filters (Pall, New York, NY, USA). The linear gradient started from $100 \%$ solvent A and decreased to $50 \%$ within $45 \mathrm{~min}$, followed by a second linear gradient to $100 \%$ solvent B within $15 \mathrm{~min}$. The column temperature was set at $25^{\circ} \mathrm{C}$ and the flow rate was $1.0 \mathrm{~mL} / \mathrm{min}$. External neat solvent calibration was performed by diluting suitable volumes of lutein standard $(90.0 \%$, Phytolab, Dutendorfer, Germany), and the calibration curve was shown to have a regression equation as follows:

$$
y=1.6972 x+0.3104(R 2=0.9999) .
$$

\subsection{Antioxidant Activity Measurement}

The changes in the antioxidant activities of the noodles by marigold powder were investigated using 2,2'-diphenyl-1-picrylhydrazyl (DPPH) and 2,2-azino-bis-3-ethylbenzothiazoline-6-sulfonic acid (ABTS) assays. The freeze-dried noodle samples were ground to pass 
through a 100-mesh sieve. The ground noodle powder was agitated with 70\% ethanol at room temperature for $5 \mathrm{~h}$, followed by centrifugation at 15,000 $\times \mathrm{g}$ for $20 \mathrm{~min}$. DPPH assay was conducted based on the method reported by Sun and Ho [17], with slight modifications. The ethanol extract $(0.5 \mathrm{~mL})$ was reacted with $0.1 \mathrm{mM}$ DPPH solution $(0.5 \mathrm{~mL})$, followed by incubation at $37^{\circ} \mathrm{C}$ for $30 \mathrm{~min}$. The absorbance was recorded at $517 \mathrm{~nm}$ using a spectrophotometer (DU 730, Beckman Coulter Inc., Fullerton, CA, USA). In addition, the ABTS solution was prepared by the procedure of Bhattacharyya et al. [18]. The extract $(0.1 \mathrm{~mL})$ was added to the ABTS solution $(1 \mathrm{~mL})$, and the mixture was held at room temperature for $6 \mathrm{~min}$. The absorbance was recorded at $734 \mathrm{~nm}$. All the results were expressed as Trolox equivalent (TE) per gram of dry sample.

\subsection{Statistical Analysis}

All the experiments were conducted in triplicate. The experimental results were analyzed using the R statistical package. The analysis of variance (ANOVA) was conducted at a confidence level of 95\%, followed by Duncan's multiple range test for a mean comparison.

\section{Results and Discussion}

Figure 1a exhibits the pasting patterns of the wheat flour containing marigold powder. The pasting profiles of all the samples were distinctly characterized by peak viscosity during heating, a decrease in the viscosity during the temperature holding, and a viscosity increase during the cooling. This pasting pattern could be explained by the fact that starch granules in the wheat flour became swollen and ruptured during gelatinization and then recrystallized during retrogradation [19]. Therefore, as the wheat flour was replaced with marigold powder, the pasting parameters such as peak, through, and final viscosities became lower, which would be due mainly to the reduced level of starch granules derived from the wheat flour replacement with marigold powder. This pasting trend was also observed in preceding studies where wheat flour was replaced with corn bran [20] and $\beta$-glucan [21].

The effect of marigold powder on the thermal properties of the wheat flour was investigated as shown in Figure $1 \mathrm{~b}$. A distinct peak of starch gelatinization was clearly detected in the temperature range from 60 to $70{ }^{\circ} \mathrm{C}$. The values of the peak enthalpy required to gelatinize the starch granules in the wheat flour tended to decrease with increasing amounts of marigold powder. However, as can be seen in Figure 1b, the use of marigold powder did not significantly influence the gelatinization temperature of the wheat flour $(p>0.05)$.

The changes in the dynamic viscoelastic properties of wheat flour paste due to marigold powder were examined. Figure 2 showed the storage $\left(G^{\prime}\right)$ and loss $\left(G^{\prime \prime}\right)$ moduli of the paste samples, which are measures of the elastic and viscous nature of a material, respectively [22]. They had a tendency to increase when the frequency increased, showing frequency dependence. In addition, all the samples had higher values of storage moduli $\left(G^{\prime}\right)$ than loss moduli $\left(G^{\prime \prime}\right)$, which indicated a predominant elastic behavior. Thus, all of the samples exhibited weak-gel-like viscoelastic characteristics. It was also noted that the values of $G^{\prime}$ and $G^{\prime \prime}$ decreased with increasing levels of marigold powder. These results showed that the replacement of the wheat flour with marigold powder weakened the structure of the paste samples, consequently contributing to the reduced viscoelastic parameters. 


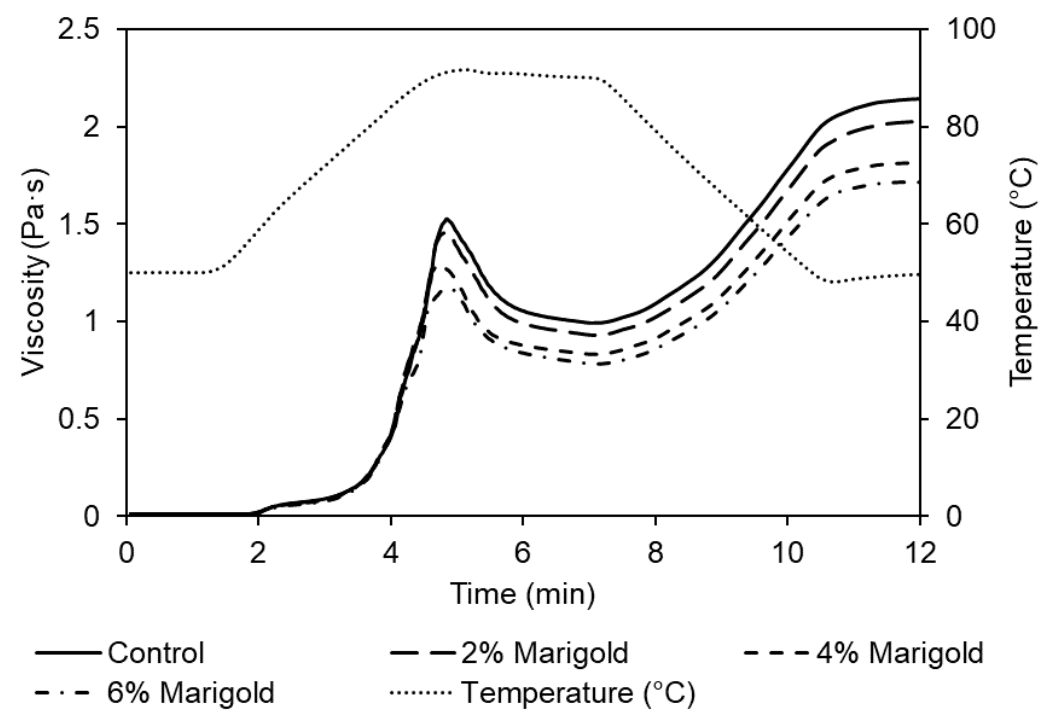

(a)

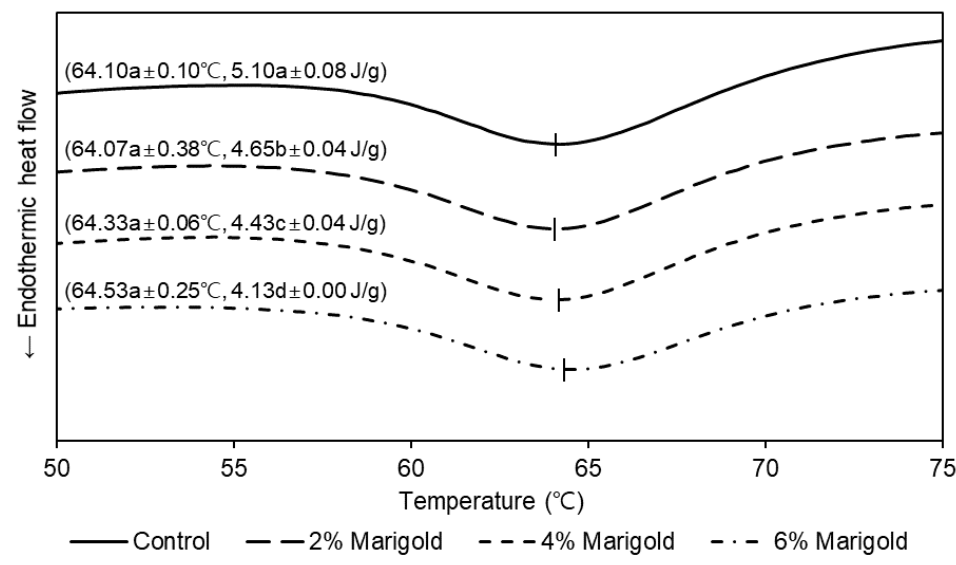

(b)

Figure 1. Effect of marigold powder on the pasting (a) and thermal (b) properties of wheat flour (means with different letters in the same column differ significantly at $p<0.05$ ).

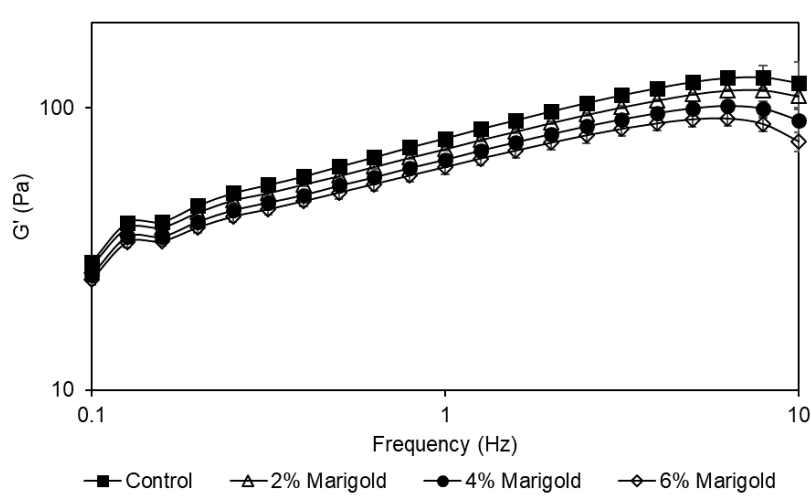

(a)

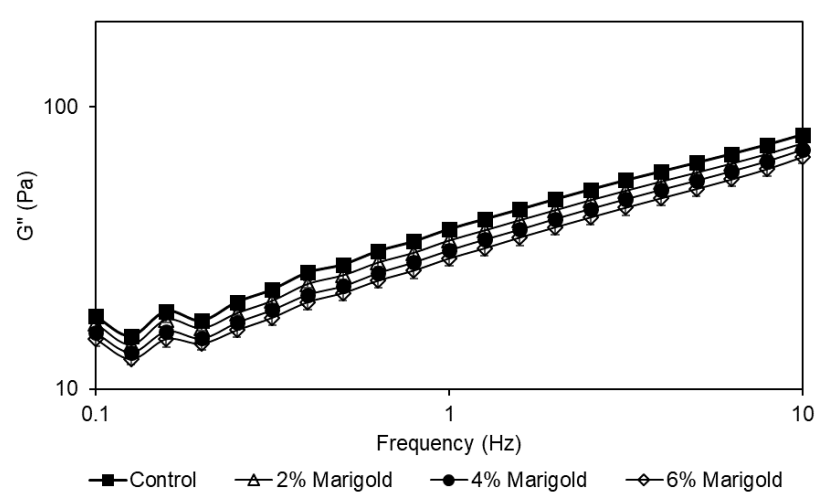

(b)

Figure 2. Changes in the viscoelastic properties of wheat flour pastes by marigold powder $\left(G^{\prime}(\mathbf{a})\right.$ and $\left.G^{\prime \prime}(\mathbf{b})\right)$. 
The microstructure of the starch paste samples with marigold powder was investigated using scanning electron microscopy. Figure 3 shows the three-dimensional structure of the paste samples with the different levels of marigold powder, exhibiting a cellular structure [23]. The paste sample without marigold powder appeared to have a dense and tight structure. However, the pores became larger in the paste samples with higher levels of marigold powder, probably weakening the structural network. Therefore, it appear that these structural changes with the addition of marigold powder were correlated with the reduced viscoelastic parameters as already mentioned in Figure 2.

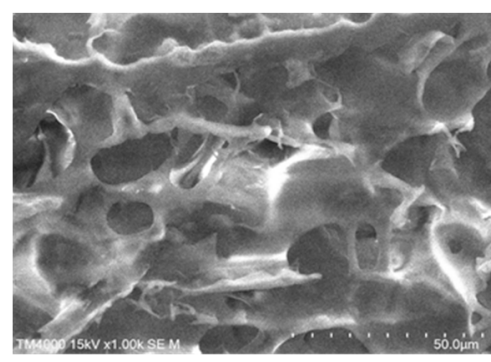

Control

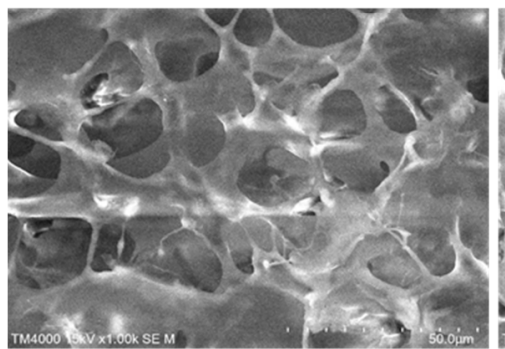

$4 \%$ Marigold

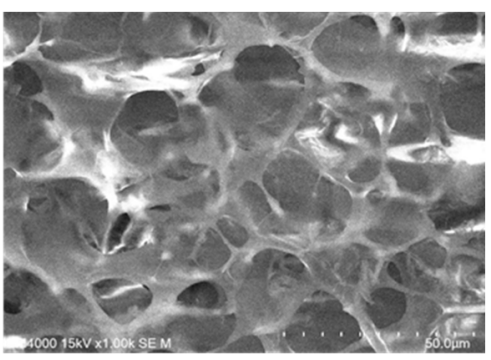

$2 \%$ Marigold

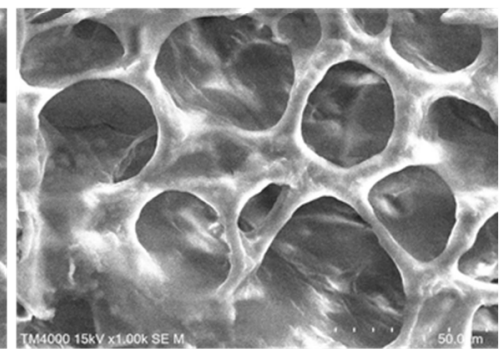

$6 \%$ Marigold

Figure 3. Microstructural changes of wheat flour pastes by marigold powder $(\times 1000$ magnification $)$.

The cooking properties of the noodles prepared with marigold powder were investigated, and results are shown in Figure 4. It is well-recognized that solid components in noodles are released to cooking water when the noodles are cooked in hot water, consequently leading to a cooking loss [24]. Since a high cooking loss is related to a sticky noodle texture and viscous liquid, the cooking loss is recognized as one of important quality measures for noodles. Figure 4 shows the effect of marigold powder on the cooking properties of the noodles cooked for 3 and $6 \mathrm{~min}$. The use of marigold powder at a level of $2 \%$ and $4 \%$ did not significantly affect the cooking loss and water absorption of the noodles after cooking, respectively. However, the samples prepared with a high level of marigold powder exhibited higher cooking loss and lower water absorption. The decreased water absorption of the noodles with marigold powder could be correlated with the reduced pasting parameters, specifically peak viscosity, which is known to be closed related to starch swelling volume [25]. 


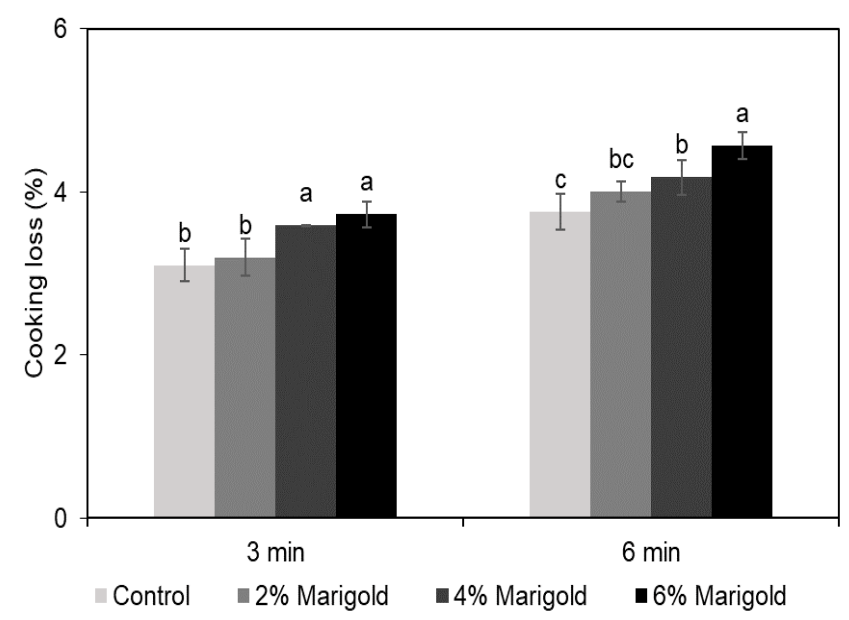

(a)

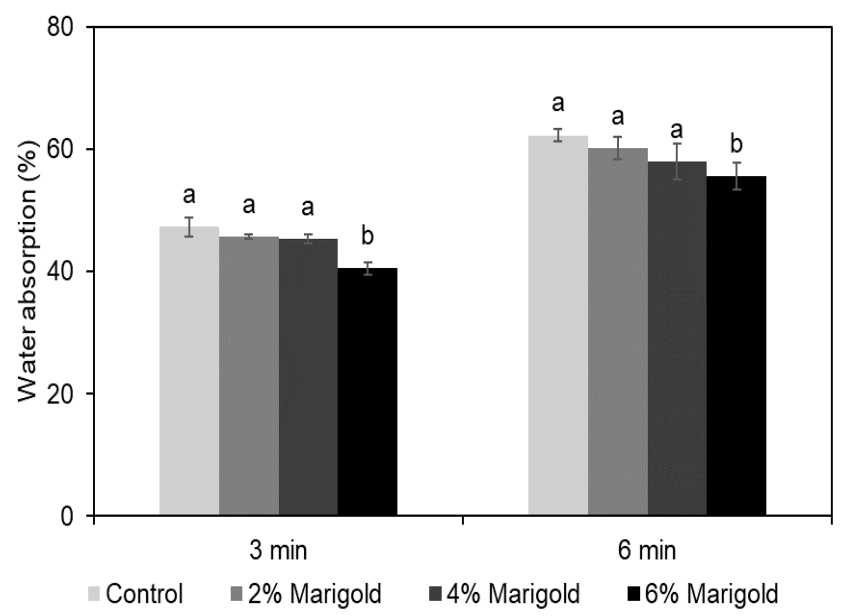

(b)

Figure 4. Effect of marigold powder on the cooking loss (a) and water absorption (b) of fresh noodles (means with different letters on the bars differ significantly at $p<0.05$ ).

These results were closely correlated with the structural characteristics of the noodles with marigold powder (see Figure 3).

Table 1 shows the effect of marigold powder on the textural properties of marigoldpowder-incorporated wheat noodles, which were measured using a Kieffer dough and gluten extensibility rig. After cooking, the maximum resistance required to extend noodles (Rmax) and the distance at the maximum force (E) [26] were evaluated. The control sample without marigold powder had the highest value of Rmax $(1.74 \mathrm{~N})$ and $\mathrm{E}(19.14 \mathrm{~mm})$, whereas the use of marigold powder for the wheat flour significantly reduced values of both Rmax and E. However, when marigold powder was incorporated at a level of $2 \%(w / w)$, there were no significant differences in the tensile properties (Rmax) from the control sample.

Table 1. Effect of marigold powder on the tensile properties of noodles after cooking (means with different letters in the same row differ significantly at $p<0.05$ ).

\begin{tabular}{ccccc}
\hline & Control & $\mathbf{2 \%}$ Marigold & $\mathbf{4 \%}^{\text {\%arigold }}$ & $\mathbf{6 \%}^{\text {\%arigold }}$ \\
\hline $\operatorname{Rmax}(\mathrm{N})$ & $1.74 \pm 0.15^{\mathrm{a}}$ & $1.66 \pm 0.08^{\mathrm{a}}$ & $1.27 \pm 0.08^{\mathrm{b}}$ & $1.11 \pm 0.09^{\mathrm{c}}$ \\
$\mathrm{E}(\mathrm{mm})$ & $19.14 \pm 1.46^{\mathrm{a}}$ & $16.26 \pm 1.34^{\mathrm{b}}$ & $15.68 \pm 0.97^{\mathrm{b}}$ & $15.06 \pm 0.79^{\mathrm{b}}$ \\
\hline
\end{tabular}

The HPLC analysis demonstrated that the level of lutein in the marigold powder was determined to be $2.639 \%$ (data not shown). This result could be favorably compared with the lutein contents of the different marigold cultivars in preceding studies, which were reported to be in the range of $0.831-2.059 \%$ for the petals [27] and $0.126-0.272$ for the flowers [28]. The levels of lutein in the marigold-powder-incorporated fresh noodles were quantitatively analyzed before and after cooking using the HPLC. As shown in Figure 5, the contents of lutein in the noodles increased when the amounts of marigold powder were increased, whereas lutein was not detected in the control noodle sample made from wheat flour without marigold powder. Before cooking, the levels of lutein in the noodles prepared with marigold powder ranged from 61.2 to $204.9 \mathrm{mg} / 100 \mathrm{~g}$ noodle. After cooking, the levels of lutein in the noodles decreased to $37.1-144.6 \mathrm{mg} / 100 \mathrm{~g}$ noodle. Thus, the cooking process led to a distinct decrease in the content of lutein by almost $50 \%$. This could be due to the heat labile feature of lutein, which was reported in preceding studies in which the level of lutein in whole grains [29] and vegetable oils [30] was reduced due to exposure to high temperatures. Furthermore, as mentioned in the cooking loss results (Figure $4 a$ ), the higher cooking loss of the noodles with marigold powder seemed to cause 
lutein to be reduced. It is recommended to take $10 \mathrm{mg} /$ day of lutein for improving visual functions [31]. Although the levels of lutein in the noodles were reduced after cooking, it appeared that they were enough to satisfy this recommendation.

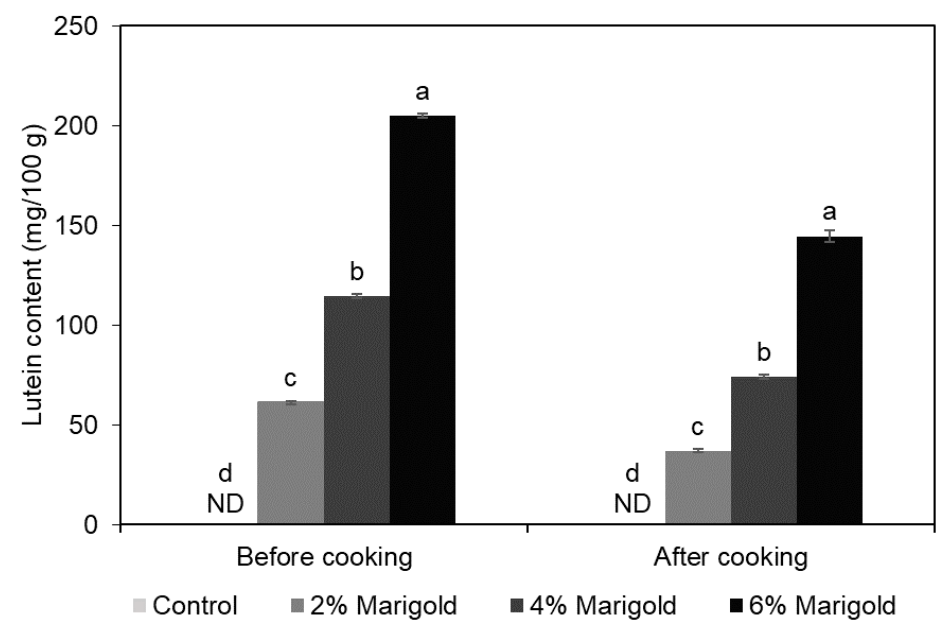

Figure 5. The lutein contents of the noodles prepared with marigold powder before and after cooking (ND: not detected, means with different letters on the bars differ significantly at $p<0.05$ ).

It is widely reported that marigold extracts have great abilities to scavenge radicals [32]. Thus, the effect of marigold powder on the antioxidant capacities of the noodles was examined before and after cooking. As shown in Figure 6, the antioxidant activities were expressed as Trolox equivalents. It was noted that the antioxidant activities of the noodles containing marigold powder were higher in both the DPPH (Figure 6a) and ABTS (Figure $6 b$ ) assays than those of the samples prepared without marigold powder. Furthermore, the scavenging activities had a tendency to increase when the amounts of marigold powder were increased. Thus, it was obvious that marigold powder positively contributed to enhancing the antioxidant capacities of the noodles. In addition, the antioxidant activities of the noodles were significantly reduced by almost $30 \%$ after cooking. This result could be explained by the fact that the cooking process led to the oxidative degradation of antioxidant compounds [33]. Also, as mentioned in Figure 4, the reduced antioxidant capacities might result from the leaching of the antioxidants from the noodles to the cooking water during cooking [34].

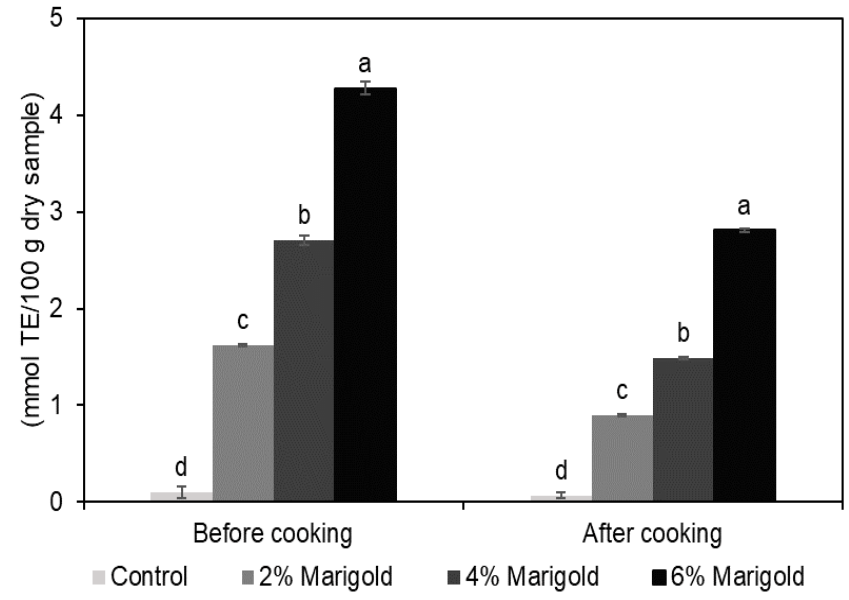

(a)

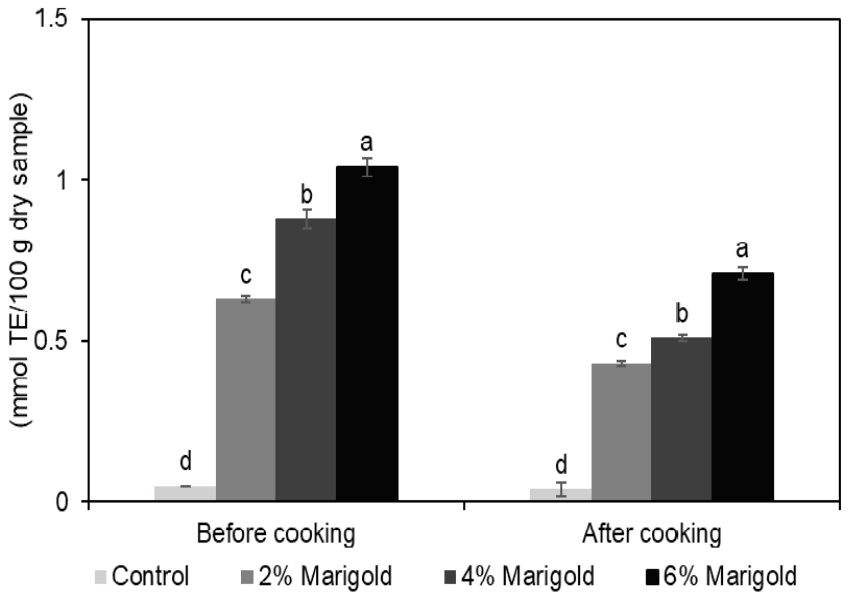

(b)

Figure 6. The antioxidant activities of the noodles prepared with marigold powder before and after cooking (DPPH (a) and ABTS (b)) (means with different letters on the bars differ significantly at $p<0.05)$. 


\section{Conclusions}

Marigold powder was incorporated as a good source of lutein into the formulation of fresh noodles for lutein fortification, and its effects on the thermo-rheological, structural, and antioxidant properties of the noodles were characterized. The pasting and dynamic viscoelastic parameters of the wheat flour were reduced by increasing the levels of marigold powder, which weakened the cellular microstructure. However, the use of marigold powder at a level of $2 \%$ did not significantly affect the cooking and textural properties of the noodles. Moreover, the noodles prepared with marigold powder contained a high content of lutein (61.2-204.9 mg/100 g before cooking and 37.1-144.6 mg/100 g after cooking) that positively contributed to enhancing their antioxidant activities. Thus, this study may provide fundamental information related to the processing performance of marigold powder in a food system, which could give the food industry more potential opportunities to develop new functional food products for eye health using lutein fortification without significant quality loss. Further studies are necessary to extend the application of marigold powder as an excellent source of lutein to a wider variety of food products.

Author Contributions: Conceptualization, S.N. and S.L.; methodology, S.N., C.-Y.L., S.-M.S. and S.L.; investigation, S.N., C.-Y.L. and S.L.; data curation, S.N., S.-M.S. and S.L.; writing-original draft preparation, S.N., D.-U.L. and S.L.; writing-review and editing, S.N., S.-M.S., D.-U.L. and S.L.; supervision, S.L.; project administration, D.-U.L. and S.L.; funding acquisition, D.-U.L. and S.L. All authors have read and agreed to the published version of the manuscript.

Funding: This research was supported by Innovative Food Product and Natural Food Materials Development Program, Ministry for Food, Agriculture, Forestry and Fisheries, Republic of Korea (320015-02).

Institutional Review Board Statement: Not applicable.

Informed Consent Statement: Not applicable.

Data Availability Statement: Not applicable.

Conflicts of Interest: The authors declare no conflict of interest.

\section{References}

1. Sheppard, A.L.; Wolffsohn, J.S. Digital eye strain: Prevalence, measurement and amelioration. BMJ Open Ophthalmol. 2018, 3. [CrossRef] [PubMed]

2. Seddon, J.M.; Ajani, U.A.; Sperduto, R.D.; Hiller, R.; Blair, N.; Burton, T.C.; Farber, M.D.; Gragoudas, E.S.; Haller, J.; Miller, D.T. Dietary carotenoids, vitamins A, C, and E, and advanced age-related macular degeneration. JAMA 1994, 272, 1413-1420. [CrossRef] [PubMed]

3. Lim, L.S.; Mitchell, P.; Seddon, J.M.; Holz, F.G.; Wong, T.Y. Age-related macular degeneration. Lancet 2012, 379, 1728-1738. [CrossRef]

4. Researchandmarkets. Available online: https://www.researchandmarkets.com/reports/4758369/vision-care-market-globaloutlook-and-forecast (accessed on 30 December 2020).

5. Salanță, L.C.; Uifălean, A.; Iuga, C.-A.; Tofană, M.; Cropotova, J.; Pop, O.L.; Pop, C.R.; Rotar, M.A.; Bautista-Ávila, M.; González, C.V. Valuable Food Molecules with Potential Benefits for Human Health. In The Health Benefits of Foods-Current Knowledge and Further Development; IntechOpen: London, UK, 2020.

6. Bone, R.A.; Landrum, J.T.; Friendes, L.M.; Gomez, C.M.; Kilburn, M.D.; Menendez, E.; Vidal, I.; Wang, W. Distribution of lutein and zeaxanthin stereoisomers in the human retina. Exp. Eye. Res. 1997, 64, 211-218. [CrossRef] [PubMed]

7. Roberts, R.L.; Green, J.; Lewis, B. Lutein and zeaxanthin in eye and skin health. Clin. Dermatol. 2009, 27, 195-201. [CrossRef] [PubMed]

8. Gale, C.R.; Hall, N.F.; Phillips, D.I.; Martyn, C.N. Lutein and zeaxanthin status and risk of age-related macular degeneration. Investig. Ophthalmol. Vis. Sci. 2003, 44, 2461-2465. [CrossRef]

9. Kijlstra, A.; Tian, Y.; Kelly, E.R.; Berendschot, T.T. Lutein: More than just a filter for blue light. Prog. Retin. Eye Res. 2012, 31, 303-315. [CrossRef]

10. Ishida, B.K.; Chapman, M.H. Carotenoid extraction from plants using a novel, environmentally friendly solvent. J. Agric. Food Chem. 2009, 57, 1051-1059. [CrossRef]

11. Perry, A.; Rasmussen, H.; Johnson, E.J. Xanthophyll (lutein, zeaxanthin) content in fruits, vegetables and corn and egg products. J. Food Compos. Anal. 2009, 22, 9-15. [CrossRef]

12. Šivel, M.; Kráčmar, S.; Fišera, M.; Klejdus, B.; Kubáň, V. Lutein content in marigold flower (Tagetes erecta L.) concentrates used for production of food supplements. Czech J. Food Sci. 2014, 32, 521-525. [CrossRef] 
13. Kumar, A.; Kaur, A.; Tomer, V.; Gupta, K.; Kaur, K. Effect of Rose Syrup and Marigold Powder on the Physicochemical, Phytochemical, Sensorial and Storage Properties of Nutricereals and Milk-Based Functional Beverage. J. Am. Coll. Nutr. 2020, 1-8. [CrossRef]

14. Ahluwalia, P.; Kaur, A.; Thillon, G.K. Effect of dried marigold flower powder as a source of natural color on rheological properties of flour. Int. J. Food Nutr.Saf. 2014, 5, 63-73.

15. Liu, Y.; Perera, C.O.; Suresh, V. Comparison of three chosen vegetables with others from South East Asia for their lutein and zeaxanthin content. Food Chem. 2007, 101, 1533-1539. [CrossRef]

16. Moros, E.; Darnoko, D.; Cheryan, M.; Perkins, E.; Jerrell, J. Analysis of xanthophylls in corn by HPLC. J. Agric. Food Chem. 2002, 50, 5787-5790. [CrossRef] [PubMed]

17. Sun, T.; Ho, C.-T. Antioxidant activities of buckwheat extracts. Food Chem. 2005, 90, 743-749. [CrossRef]

18. Bhattacharyya, S.; Datta, S.; Mallick, B.; Dhar, P.; Ghosh, S. Lutein content and in vitro antioxidant activity of different cultivars of Indian marigold flower (Tagetes patula L.) extracts. J. Agric. Food Chem. 2010, 58, 8259-8264. [CrossRef]

19. Crosbie, G.B.; Ross, A.S. RVA Handbook; AACC International: Saint Paul, MN, USA, 2007.

20. Baek, J.-J.; Kim, Y.; Lee, S. Functional characterization of extruded rice noodles with corn bran: Xanthophyll content and rheology. J. Cereal Sci. 2014, 60, 311-316. [CrossRef]

21. Kim, J.; Lee, S.M.; Bae, I.Y.; Park, H.G.; Gyu Lee, H.; Lee, S. (1-3)(1-6)- $\beta$-Glucan-enriched materials from Lentinus edodes mushroom as a high-fibre and low-calorie flour substitute for baked foods. J. Sci. Food Agric. 2011, 91, 1915-1919. [CrossRef]

22. Steffe, J.F. Rheological Methods in Food Process Engineering; Freeman Press: East Lansing, MI, USA, 1996.

23. Han, X.Z.; Hamaker, B.R. Functional and microstructural aspects of soluble corn starch in pastes and gels. Starke 2000, 52, 76-80. [CrossRef]

24. Chansri, R.; Puttanlek, C.; Rungsadthogy, V.; Uttapap, D. Characteristics of clear noodles prepared from edible canna starches. J. Food Sci. 2005, 70, S337-S342. [CrossRef]

25. Crosbie, G.B. The relationship between starch swelling properties, paste viscosity and boiled noodle quality in wheat flours. J. Cereal Sci. 1991, 13, 145-150. [CrossRef]

26. Heo, S.; Lee, S.M.; Shim, J.-H.; Yoo, S.-H.; Lee, S. Effect of dry-and wet-milled rice flours on the quality attributes of gluten-free dough and noodles. J. Food Eng. 2013, 116, 213-217. [CrossRef]

27. Ingkasupart, P.; Manochai, B.; Song, W.T.; Hong, J.H. Antioxidant activities and lutein content of 11 marigold cultivars (Tagetes spp.) grown in Thailand. Food Sci. Technol. 2015, 35, 380-385. [CrossRef]

28. Lin, J.-H.; Lee, D.-J.; Chang, J.-S. Lutein in specific marigold flowers and microalgae. J. Taiwan Inst. Chem. Engrs. 2015, 49, 90-94. [CrossRef]

29. Abdel-Aal, E.-S.M.; Young, J.C.; Akhtar, H.; Rabalski, I. Stability of lutein in wholegrain bakery products naturally high in lutein or fortified with free lutein. J. Agric. Food Chem. 2010, 58, 10109-10117. [CrossRef]

30. Vaidya, B.; Choe, E. Effects of seed roasting on tocopherols, carotenoids, and oxidation in mustard seed oil during heating. J. Am. Oil Chem. Soc. 2011, 88, 83-90. [CrossRef]

31. Zhao, L.; Sweet, B.V. Lutein and zeaxanthin for macular degeneration. Am. J. Health Syst. Pharm. 2008, 65, 1232-1238. [CrossRef]

32. Gong, Y.; Liu, X.; He, W.-H.; Xu, H.-G.; Yuan, F.; Gao, Y.-X. Investigation into the antioxidant activity and chemical composition of alcoholic extracts from defatted marigold (Tagetes erecta L.) residue. Fitoterapia 2012, 83, 481-489. [CrossRef]

33. Fares, C.; Platani, C.; Baiano, A.; Menga, V. Effect of processing and cooking on phenolic acid profile and antioxidant capacity of durum wheat pasta enriched with debranning fractions of wheat. Food Chem. 2010, 119, 1023-1029. [CrossRef]

34. Kong, S.; Kim, D.J.; Oh, S.K.; Choi, I.S.; Jeong, H.S.; Lee, J. Black rice bran as an ingredient in noodles: Chemical and functional evaluation. J. Food Sci. 2012, 77, C303-C307. [CrossRef] 